\title{
Suicidal ideation and attempts among people with severe mental disorder, Addis Ababa, Ethiopia, comparative cross-sectional study
}

\author{
Bereket Duko ${ }^{1^{*}}$ (D) and Getinet Ayano ${ }^{2}$
}

\begin{abstract}
Background: People with severe mental disorders are associated with increased risk of suicide and suicide attempts compared to the general population. In low and middle-income countries, research concerning suicide attempts and completed suicide among people living with severe mental disorder is limited. The objective of this study was to assess suicide and attempts in people with severe mental disorder at Amanuel Mental Specialized Hospital, Addis Ababa, Ethiopia.

Methods: Institution-based cross-sectional study was conducted in August-September 2016. Patients with schizophrenia and bipolar disorder were selected using systematic random-sampling technique. The composite international diagnostic interview was used to assess suicide that was administered by psychiatry professionals. Substance use disorder was assessed through face-to-face interviews using structured clinical interview of DSM-IV.

Results: A total of 542 (272 schizophrenia +270 bipolar disorder) patients were included in the study. One hundred nineteen (43.75\%) of schizophrenic participants and 128 (47.1\%) of bipolar participants have suicidal ideation. Fiftysix (20.7\%) of schizophrenic participants and 58 (21.3\%) of bipolar participants have suicidal attempt. Among the schizophrenic and bipolar patients who had suicidal ideation, 31.8 and $32.60 \%$ had co-morbid substance use disorder, respectively.

Conclusion: In this study, which was performed in Ethiopia, suicidal ideation and attempt were shown to be common problems in people with schizophrenia and bipolar disorder. Co-morbid substance use disorder was a more frequent phenomenon among patients with suicidal ideation and attempt. Attention should be given to screen and assess suicidal ideation and attempt in persons with schizophrenia and bipolar disorder.
\end{abstract}

Keywords: Suicidal ideation, Suicidal attempt, Schizophrenia, Bipolar disorder

\section{Background}

Suicide is a huge but largely preventable health problem causing almost half of all violent deaths and resulting in one million fatalities each year, as well as economic costs in billions of dollars. Estimates suggest that suicide could rise to 1.5 million by 2020 . Globally,

\footnotetext{
*Correspondence: berkole.dad@gmail.com

${ }^{1}$ Faculty of Health Sciences, College of Medicine and Health Sciences, Hawassa University, P. O. Box 1560 Hawassa, Ethiopia

Full list of author information is available at the end of the article
}

suicide represents $1.4 \%$ of the global burden of diseases [1]. Suicide is usually a cause of great distress to victim, family, friends, and community and largely to the nation $[2,3]$.

According to different studies among all suicides over $90 \%$ of are explained by mental disorders [4-9] mostly mood disorders, alcohol and substance use disorders [9-12].

A recent review of the literatures estimated that up to $50 \%$ of schizophrenic patients attempt suicide and up to $13 \%$ of all deaths due to suicide are attributable to 
schizophrenia [13]. Compared to the general population (suicide prevalence about 1\%), people with schizophrenia have a more than eightfold increased risk of suicide [14]. Suicide is the major cause of premature death among individuals with schizophrenia. Evidences indicated that up to $10 \%$ of patients with schizophrenia die by suicide [15-17]. Being young, male, and in the early years of the illness and having a history of multiple previous episodes or previous suicide attempts are the common risk factors for suicide in schizophrenia [18-21]. A substantial percentage of patients with schizophrenia also attempt suicide, with estimates of lifetime occurrence ranging from 18 to $55 \%$ [8].

Evidences indicated that persons with bipolar disorder are 30 times more likely to make a suicide attempt during their lifetime compared to those with no psychiatric disorder [22]. Close to one-third of persons with bipolar disorder attempt suicide [23, 24]. Researchers estimate that in the general population $29 \%$ of bipolar patients made at least one suicide attempt during their lives. In clinical samples, $25-56 \%$ of the patients with BD report at least one suicide attempt during their lives and $10-19 \%$ die by suicide [22-24]. A number of factors have been reported to be associated with the occurrence of suicide attempts in bipolar disorder and co-morbid substance use disorders (SUDs) [23, 25-27] is among those factors.

In persons with severe mental disorders co-morbid substance use disorders (SUD) are very common throughout the course of illness, with an estimated prevalence of $50-60 \%$ [28-31]. Nicotine and alcohol use disorders are particularly common among persons with severe mental disorders $[8,9]$. Substance use disorder comorbidity is eventually associated with worse outcome and higher suicidal risk $[29,30]$.

Evidences have shown that people with severe mental disorders (SMD) are at higher risk of suicide. However, in low- and middle-income countries (LMIC), including Ethiopia there is limited research concerning suicide attempts and suicide ideations in people with severe mental disorders (SMDs). The objective of this study was to assess suicide and suicide attempts in people with schizophrenia and bipolar disorder.

\section{Methods}

\section{Study setting and population}

Institution-based cross-sectional study was conducted in August 2016 at Amanuel Mental Specialized Hospital, Addis Ababa, Ethiopia. Amanuel Mental specialized hospital is the only hospital in Ethiopia giving services for mental health for long time. A total of 542 patients; 272 patients with the diagnosis of schizophrenia and 270 with bipolar disorder were included in the study.
Study participants were included using systematic random-sampling technique.

\section{Inclusion and exclusion criteria}

All patients with established DSM-IV diagnoses of schizophrenia and bipolar disorder who had treatment follow-up assessment were included in this study. Suicidal gesture or attempt was defined as a self-inflicted act associated with intent to die or use of a method with potential for lethality.

\section{Data collection instruments}

Demographic variables were collected using semistructured questionnaire. Data were collected by trained psychiatry professionals. The composite international diagnostic interview (CIDI) was administered by psychiatry professionals and used to assess suicide. Substance use disorder was assessed through face-toface interviews using structured clinical interview of DSM-IV (SCID).

\section{Data processing and analyses}

The statistical program for social science (SPSS version 20) was used for data analyses. Socio-demographic (age, sex, marital status, areas of residence, religion, education) and clinical factors (diagnosis, history of alcohol, cannabis, nicotine and khat abuse or dependence) was analyzed and reported using words, tables and charts.

\section{Results}

\section{Socio-economic and demographic characteristics}

A total of 572 patients; 270 patients with the diagnosis of schizophrenia and 272 with bipolar disorder were included in the study. The mean age of the respondents was $32.62( \pm \mathrm{SD}=9.43)$ and $33.71( \pm \mathrm{SD}=9.35)$ years for bipolar and schizophrenic participants, respectively. Among the total participants (bipolar and schizophrenia), 107 (39.3\%) and 105 (38.8\%) of participants had completed secondary educational level, respectively. Regarding income, the average monthly family income was $1450( \pm \mathrm{SD}=648.50)$ and $1463( \pm \mathrm{SD}=647.93)$ Ethiopian birr with respect to bipolar and schizophrenic participants (Table 1).

\section{Suicidal ideation and attempt in patients with severe mental disorders}

One hundred nineteen (43.75\%) of schizophrenic participants and 128 (47.1\%) of bipolar patients had suicidal ideation. In addition to this, 56 (20.7\%) of schizophrenic 
Table 1 Sociodemographic characteristics of people with severe mental disorders (schizophrenia, $\mathbf{n = 2 7 0}$ and bipolar disorder, $n=272$ ) Amanuel Hospital, Addis Ababa, Ethiopia, August, 2016

\begin{tabular}{|c|c|c|c|c|}
\hline \multirow[t]{2}{*}{ Characteristics } & \multicolumn{2}{|c|}{ Schizophrenia } & \multicolumn{2}{|c|}{ Bipolar disorder } \\
\hline & Frequency & $\%$ & Frequency & $\%$ \\
\hline \multicolumn{5}{|l|}{ Sex } \\
\hline Male & 186 & 68.8 & 196 & 72.1 \\
\hline Female & 84 & 31.1 & 76 & 28.9 \\
\hline \multicolumn{5}{|l|}{ Age in years } \\
\hline $20-27$ & 105 & 38.8 & 101 & 37.2 \\
\hline $28-38$ & 96 & 35.6 & 98 & 36 \\
\hline $39-53$ & 69 & 25.6 & 73 & 26.8 \\
\hline \multicolumn{5}{|l|}{ Marital status } \\
\hline Single & 157 & 58.2 & 159 & 58.5 \\
\hline Married & 73 & 27 & 79 & 29 \\
\hline Separated & 14 & 5.2 & 14 & 5.1 \\
\hline Divorce & 26 & 9.6 & 20 & 7.4 \\
\hline \multicolumn{5}{|l|}{ Place of residence } \\
\hline Urban & 186 & 68.9 & 182 & 66.9 \\
\hline Rural & 84 & 31.1 & 90 & 33.1 \\
\hline \multicolumn{5}{|l|}{ Religion } \\
\hline Orthodox & 168 & 62.3 & 166 & 61 \\
\hline Muslim & 73 & 27 & 81 & 29.8 \\
\hline Protestant & 24 & 8.8 & 19 & 7 \\
\hline Catholic & 5 & 1.9 & 6 & 2.2 \\
\hline \multicolumn{5}{|l|}{ Educational level } \\
\hline No school & 30 & 11.1 & 27 & 9.9 \\
\hline Primary & 78 & 28.9 & 86 & 31.6 \\
\hline Secondary & 105 & 38.9 & 105 & 38.6 \\
\hline Higher education & 57 & 21.1 & 54 & 19.9 \\
\hline \multicolumn{5}{|l|}{ Occupation } \\
\hline Government employee & 23 & 8.5 & 28 & 10.2 \\
\hline Private employee & 89 & 33 & 87 & 32 \\
\hline Merchant & 56 & 20.6 & 57 & 21 \\
\hline Unemployed & 23 & 8.5 & 22 & 8.1 \\
\hline Student & 59 & 21.9 & 53 & 19.5 \\
\hline Others & 20 & 7.5 & 25 & 9.2 \\
\hline \multicolumn{5}{|l|}{ Monthly income } \\
\hline $300-1000$ & 106 & 39.2 & 107 & 39.3 \\
\hline $1001-1900$ & 92 & 34.2 & 91 & 33.5 \\
\hline $1901-3000$ & 72 & 26.6 & 74 & 27.2 \\
\hline \multicolumn{5}{|l|}{ Ethnicity } \\
\hline Amhara & 63 & 23.3 & 58 & 21.3 \\
\hline Tigray & 40 & 14.8 & 38 & 14 \\
\hline Oromo & 102 & 37.8 & 100 & 36.8 \\
\hline Gurage & 55 & 20.4 & 64 & 23.5 \\
\hline Others & 10 & 3.7 & 12 & 4.4 \\
\hline
\end{tabular}

Table 2 Distribution of patients with severe mental disorders by suicidal ideation and attempt (schizophrenia, $n=270$ and bipolar disorder, $n=272$ ) Amanuel Mental Specialized Hospital, Addis Ababa, Ethiopia, August, 2016

\begin{tabular}{llllll}
\hline \multirow{2}{*}{$\begin{array}{l}\text { Suicidal } \\
\text { behavior }\end{array}$} & \multicolumn{2}{l}{ Schizophrenia } & & \multicolumn{2}{l}{ Bipolar disorder } \\
\cline { 2 - 3 } \cline { 5 - 6 } & Yes & No & & Yes & No \\
\hline Suicidal ideation & $119(43.75 \%)$ & $151(56.25 \%)$ & & $128(47.1 \%)$ & $144(52.9 \%)$ \\
Suicidal attempt & $56(20.7 \%)$ & $214(79.3 \%)$ & & $58(21.3 \%)$ & $214(78.7 \%)$ \\
\hline
\end{tabular}

participants and 58 (21.3\%) of bipolar participants have suicidal attempt, respectively (Table 2 ).

\section{Substance use disorders in patients with schizophrenia and bipolar disorders}

Regarding khat, 137 (50.3\%) of bipolar and 125 (36.6\%) of schizophrenic patients had used in their life time. Concerning alcohol, 107 (39.1\%) of bipolar and 99 (36.6\%) schizophrenic patients had used in their life time. From schizophrenic patients, 130 (48.1\%) and bipolar patients $86(31.6 \%)$ had poly substance use disorder (Table 3 ).

\section{Discussion}

This study revealed that the magnitude of suicidal ideation and suicide attempts in patients with schizophrenia and bipolar disorder was comparable with study conducted in high-income country settings [13, 14, 22, 24]. In the current study, 119 (44.1\%) of schizophrenic participants and 128 (47.1\%) of bipolar participants have suicidal ideation and, $56(20.58 \%)$ of schizophrenic participants and $58(21.32 \%)$ of bipolar participants have suicidal attempt. This finding is in agreement with other studies [13, 22, 24].

In this study, both suicidal ideation and attempt were more commonly seen in people with bipolar disorder compared to those with schizophrenia. This finding is in agreement with other studies that reported significantly higher rates of suicide ideation and attempt among patients with bipolar disorder [13, 14, 22, 24].

Suicidal ideation and attempt are common among patients with schizophrenia and bipolar disorder as compared to evidences suicidal ideation and attempt in general population. These findings are in line with other studies that revealed significantly higher suicidal ideation and attempt in patients with severe mental disorder than general population $[9,11,12,14]$.

Our study revealed that patients with severe mental disorders are using different substances. This finding is in line with other studies [20] but higher than [31] and lower than [32, 33]. The possible reasons for this difference might be due to the difference in data collection 
Table 3 Distribution of patients with Schizophrenia and Bipolar disorder by their substance use disorders (schizophrenia, $n=270$ and bipolar disorder, $n=272$ ) Amanuel Mental Specialized Hospital, Addis Ababa, Ethiopia, August, 2016

\begin{tabular}{|c|c|c|c|c|}
\hline \multirow{2}{*}{$\begin{array}{l}\text { Substance use } \\
\text { Disorders }\end{array}$} & \multicolumn{2}{|l|}{ Schizophrenia } & \multicolumn{2}{|l|}{ Bipolar disorder } \\
\hline & Current use disorder & $\begin{array}{l}\text { Life time use (ever had } \\
\text { used) disorder }\end{array}$ & Current use disorder & $\begin{array}{l}\text { Life time use (ever } \\
\text { had used) disorder }\end{array}$ \\
\hline Alcohol use disorder & $71(27.3 \%)$ & $99(36.6 \%)$ & $74(28.4 \%)$ & $107(39.1 \%)$ \\
\hline Khat/chat use disorder & $123(47.3 \%)$ & $125(46.3 \%)$ & $130(49.8 \%)$ & $137(50.3 \%)$ \\
\hline Nicotine use disorder & $34(13.1 \%)$ & $34(13.1 \%)$ & $33(12.6 \%)$ & $34(13 \%)$ \\
\hline Cannabis use disorder & $4(1.5 \%)$ & $4(1.5 \%)$ & $4(1.5 \%)$ & $4(1.5 \%)$ \\
\hline Any substance use disorder & $160(61.5 \%)$ & $165(63.5 \%)$ & 167 (64\%) & $172(65.9 \%)$ \\
\hline Poly substance use disorders & 95 (36.5\%) & $130(48.1 \%)$ & $71(27.2 \%)$ & $86(31.6 \%)$ \\
\hline
\end{tabular}

instrument, socio-demographics and culture. Unlike other studies [32-35], 132 (50.6\%) (bipolar patients) and 125 (48.1\%) (schizophrenic patients), had used khat in their life time. The possible reasons for this difference might be due to differences in socio-demographics and culture.

\section{Conclusion}

Suicidal ideation and attempt were more commonly seen in people with bipolar disorder compared to those with schizophrenia. Co-morbid substance use disorder was a more frequent phenomenon among patients with suicidal ideation and attempt than those without suicidal ideation and attempt was identified in the current study that majority of those who have history of suicidal ideation and attempt have co-occurring substance use disorders as compared to those who have no suicidal ideation and attempt. Co-morbid substance use disorders are common in person with suicidal ideation and attempt. As a result, this indicates the need for further screening and attention of co-morbidity in persons with suicide. Further studies concerning effects and specific relationships between suicide and co-morbid substance use disorders and exploring other factors are recommended.

\section{Limitation of study}

This study only assessed the descriptive part. It will be better to asses factors associated with suicidal ideation and attempt.

\section{Authors' contributions}

Both authors conceived the study and were involved in the study design, reviewed the article, analysis, report writing and drafted the manuscript. Both authors read and approved the final manuscript.

\section{Author details}

1 Faculty of Health Sciences, College of Medicine and Health Sciences, Hawassa University, P. O. Box 1560 Hawassa, Ethiopia. ${ }^{2}$ Research and Training Directorate, Amanuel Mental Specialized Hospital, Addis Ababa, Ethiopia.
Acknowledgements

The authors acknowledge Amanuel Mental Specialized Hospital, Ethiopia for funding the study. The authors appreciate the study participants for their cooperation in providing the necessary information.

\section{Competing interests}

The authors declare that they have no competing interests.

\section{Availability of data and materials}

Because the sensitivity of the data, the data will not be shared publically but upon request we will avail the necessary data for concerned body.

\section{Consent for publication}

Not applicable.

\section{Ethics approval and consent to participate}

Ethical clearance was obtained from the Institutional Review Board of Amanuel Mental Specialized Hospital. Written informed consent was obtained (after capacity to consent test) from each study participant (care giver) after they were introduced to the purpose of the study and informed about their rights to interrupt the interview at any time. Confidentiality was maintained at all levels of the study.

\section{Funding}

Amanuel Mental Specialized Hospital, Addis Ababa, Ethiopia partially funded the research work.

\section{Publisher's Note}

Springer Nature remains neutral with regard to jurisdictional claims in published maps and institutional affiliations.

Received: 22 February 2018 Accepted: 25 May 2018

Published online: 01 June 2018

\section{References}

1. World Health Organization. Suicide huge but preventable public health problem. Geneva: WHO; 2004.

2. Gelden M, Gath D, Mayou R. Concise oxford text book of psychiatry. 9th ed. Oxford: Oxford University Press; 1993. p. 255-61.

3. Jacobsson L, Renberg ES. On suicide and suicide prevention as a public health issue. Med Arh. 1999;53(3):175-7.

4. Cavanagh JT, Carson AJ, Sharpe M, Lawrie SM. Psychological autopsy studies of suicide: a systematic review. Psychol Med. 2003;33(3):395-405.

5. Hawton K, Appleby L, Platt S, Foster T, Cooper J, Malmberg A, Simkin S. The psychological autopsy approach to studying suicide: a review of methodological issues. J Affect Disord. 1998:50(2-3):269-76.

6. APA. Practice guideline for the assessment and treatment of patients with suicidal behaviors. Am J Psychiatry. 2003;160(Supp. 11):1-6. 
7. CDC. Web-based injury statistics query and reporting system (WISQARSTM). National center injury prevention and control: center for disease control; 2009.

8. Uwakwe R, Gureje O. The relationship of comorbidity of mental and substance use disorders with suicidal behaviors in the Nigerian survey of mental health and wellbeing. Soc Psychiatry Psychiatr Epidemiol. 2011:46(3):173-80.

9. WHO. Suicide prevention (SUPRE). Geneva: WHO; 2012.

10. Joe S, Stein DJ, Seedat S, Herman A, Williams DR. Prevalence and correlates of non-fatal suicidal behaviour among South Africans. Br J Psychiatry. 2008;192(4):310-1.

11. Cassidy F. Risk factors of attempted suicide in bipolar disorder. Suicide Life Threat Behav. 2011;41(1):6-11.

12. Posada-Villa J, Camacho JC, Valenzuela JI, Arguello A, Cendales JG, Fajardo R. Prevalence of suicide risk factors and suicide-related outcomes in the national mental health study, Colombia. Suicide Life Threat Behav. 2009;39(4):408-24.

13. Caldwell CB, Gottesman II. Schizophrenia—a high-risk factor for suicide: clues to risk reduction. Suicide Life Threat Behav. 1992;22:47-493.

14. Caldwell CB, Gottesman II. Schizophrenics kill themselves too: a review of risk factors for suicide. Schizophr Bull. 1990;16:571-89.

15. Miles CP. Conditions predisposing to suicide: a review. J Nerv Ment Dis. 1977;164:231-46

16. Roy A. Suicide in schizophrenia. In: Roy A, editor. Suicide. Baltimore: Williams \& Wilkins; 1986. p. 97-109.

17. Drake RE, Gates C, Whitaker A, Cotton PG. Suicide among schizophrenics: a review. Compr Psychiatry. 1985;26:90-100.

18. Johns CA, Stanley M, Stanley B. Suicide in schizophrenia. In: Mann JJ, Stanley M, editors. Psychobiology of suicidal behavior. New York: New York Academy of Sciences; 1986. p. 294-300.

19. Caldwell CB, Gottesman II. Schizophrenia—a high-risk factor for suicide: clues to risk reduction. Suicide Life Threat Behav. 1992;22:479-93.

20. Haas GL. Suicidal behavior in schizophrenia. In: Maris RW, Silverman NM, Canetto SS, editors. Review of suicidology, 1997. New York: Guilford Press; 1997. p. 202-36.

21. Chen YW, Dilsaver SC. Lifetime rates of suicide attempts among subjects with bipolar and unipolar disorders relative to subjects with other Axis I disorders. Biol Psychiatry. 1996;39:896-9.

22. Goodwin FK, Jamison KR. Maniac-depressive illness: bipolar disorders and recurrent depression. 2nd ed. New York: Oxford University Press; 2007.
23. Harris EC, Barraclough B. Suicide as an outcome for mental disorders: a meta-analysis. Br J Psychiatry. 1997;170:205-28.

24. Dunner DL, Gershon ES, Goodwin FK. Heritable factors in the severity of affective illness. Biol Psychiatry. 1976;11:31-42.

25. Endicott J, Nee J, Andeasen N, Clayton P, Keller M, Coryell W. Combine or keep separate? J Affect Disord. 1985;8(1):17-28.

26. Vieta E, Benabarre A, Colom F, Gasto C, Nieto E, Otero A, Vallejo J. Suicidal behavior in bipolar I and bipolar II disorder. J Nerv Ment Disord. 1997;185(6):407-9.

27. American Psychiatric Association. Diagnostic and statistical manual of mental disorders. 4th ed. Washington, D.C.: American Psychiatric Press; 1994.

28. Center for Substance Abuse Treatment. Substance abuse treatment for persons with co-occurring disorders. Treatment improvement protocol (TIP) Ser., No. 42. DHHS Publ. No. (SMA) 05-3992. Rockville: Substance Abuse and Mental Health Services Administration and Center for Mental Health Services; 2005

29. Center for Substance Abuse Treatment. Definitions and terms relating to co-occurring disorders. COCE overview paper. DHHS Publ. No. (SMA) 07-4163. Rockville: Substance Abuse and Mental Health Services Administration and Center for Mental Health Services; 2007.

30. Center for Substance Abuse Treatment. The epidemiology of co-occurring substance use and mental disorders. COCE overview paper 8. DHHS Publ. No. (SMA) 07-4308. Rockville: Substance Abuse and Mental Health Services Administration and Center for Mental Health Services; 2007.

31. Ashton K, Streem D. Nicotine dependence: disease management project. Lyndhurst: Centre for Continuing Education. Cleveland Clinic; 2006

32. Cassidy F, Ahearn EP, Carroll BJ. Substance abuse in bipolar disorder. Bipolar Disord. 2001;3:e120-88.

33. Tohen M, Greenfield SF, Weiss RD, Zarate CA Jr, Vagge LM. The effect of comorbid substance use disorders on the course of bipolar disorder: a review. Harv Rev Psychiatry. 1998;6:133-41.

34. Dalton EJ, Cate-Carter TD, Mundo E, Parikh SV, Kennedy JL. Suicide risk in bipolar patients: the role of co-morbid substance use disorders. Bipolar Disord. 2003;5:58-61.

35. Regier DA, Farmer ME, Rae DS, Locke BZ, Keith SJ, et al. Comorbidity of mental disorders with alcohol and other drug abuse. Results from the epidemiologic catchment area (ECA) study. JAMA. 1990;264:2511-8.
Ready to submit your research? Choose BMC and benefit from:

- fast, convenient online submission

- thorough peer review by experienced researchers in your field

- rapid publication on acceptance

- support for research data, including large and complex data types

- gold Open Access which fosters wider collaboration and increased citations

- maximum visibility for your research: over $100 \mathrm{M}$ website views per year

At BMC, research is always in progress.

Learn more biomedcentral.com/submissions 